\title{
FISCAL STIMULUS ON BAYESIAN DSGE MODELS
}

\section{Kuo-Hsuan Chin*}

\begin{abstract}
I take a Bayesian approach to estimate and forecast the effects of fiscal stimulus in various versions of the model by Smets and Wouters (2007) for the US economy. Specifically, I proxy various simpler DSGE sub-models by imposing a tight prior on a single parameter or a combination of tight priors on multiple parameters in the Smets-Wouters model. I find that the present-value government spending multipliers obtained are all in a reasonable range. Moreover, I forecast the effect of fiscal stimulus in a scenario similar to the $2008 / 2009$ recession in the US, where the public expects a large and temporary increase in government spending to stimulate a fragile economy. The forecasts, generated individually by a group of representative models, are weighted averaging by means of the posterior model probabilities that are computed on the basis of their corresponding marginal data densities. According to the Diebold-Mariano test, I find that the forecast error of the combination forecast, computed via Bayesian model averaging (BMA), is statistically larger than the individual forecast, obtained only from the one that has the best fit among those DSGE models.
\end{abstract}

Keywords: Bayesian approach, Bayesian model averaging, government spending multipliers JEL Classification: E62, E65

\section{Introduction}

The financial crisis that the US economy suffered in 2008 has drawn policymakers' attention to the effect of fiscal policy. In February 2009, the US Congress passed a \$787 billion American Recovery and Reinvestment Act (ARRA) to stimulate the fragile economy. In academia, this policy action has reignited interest in the short-run and longrun effects of a large and temporary fiscal stimulus. A variety of macroeconomic or time series models have been proposed recently to compute the fiscal multipliers. ${ }^{1}$ Cogan et al. (2010) state that the estimated structural Dynamic Stochastic General Equilibrium (DSGE) models are the appropriate candidates for measuring the quantitative effect of government spending, since they include rational economic agents optimizing their decisions over time in response to change in government spending. Unlike the Structural Vector Autoregression (SVAR) models, they are grounded in a microeconomic framework and may provide robust estimates for fiscal policymakers even with changes in policy rules. However, the estimated effects of fiscal stimulus in DSGE models vary in a wide range.

\footnotetext{
* Kuo-Hsuan Chin, Department of Economics, Feng Chia University, Taichung City, Taiwan (khchin@fcu.edu.tw).

1 Whalen and Reichling (2015) review a variety of recent macroeconomic models that economists commonly use to estimate the fiscal stimulus.
} 
In a neoclassical framework, Baxter and King (1993) argue that the degree of dynamic interaction between labour and capital is critical for determining the size of output multipliers in a model without any nominal or real frictions. Specifically, the multipliers are larger when there exists a strong dynamic interaction between labour and capital. However, Woodford (2011) finds a large crowding-out effect of fiscal stimulus with a much smaller output multiplier in a similar framework. Burnside et al. (2004) augment the neoclassical model by adding two real frictions to the model: the external habit formation on consumption and investment adjustment costs in particular. They argue that the modified model can improve the performance of the neoclassical model and that it does a particularly good job in explaining the qualitative and quantitative effects of a government spending shock.

In a small-scale New Keynesian framework, Christiano et al. (2011) argue that the output multipliers are relatively large when researchers consider a non-separable preference specification. Davig and Leeper (2011) argue that the size of output multipliers essentially depends on how the fiscal and monetary policies interact. In particular, output multipliers are smaller when policymakers conduct aggressive monetary policy. In a medium-scale New Keynesian framework, Cogan et al. (2010) find that the output multiplier is much smaller than one, due to a strong crowding-out effect on private spending caused by government spending. ${ }^{2}$ However, Zubairy (2013) finds a crowding-in effect on consumption when the model takes into account deep habit formation in households' consumption behaviour. Table 1 summarizes the methodology and the results found in the previous studies discussing the effects of fiscal stimulus.

I take a top-down approach by generalizing the structural DSGE model of Smets and Wouters (2007) for the US economy.The Smets-Wouters model is a medium-scale New Keynesian model which has proven effective for policy evaluation. Smets and Wouters (2007) argue that the model fits the US data well and that its forecasting performance is competitive with other reduced-form models such as VARs. Most importantly, many DSGE models in the literature can be viewed as simpler versions of the Smets-Wouters model after removing certain nominal or real frictions. I revisit the government spending multipliers in various versions of the Smets-Wouters model and study whether the results found in various models are comparable to the related studies.

I take a Bayesian approach to estimate and forecast the effects of fiscal stimulus in different types of DSGE models. To be precise, I proxy various simpler DSGE submodels by imposing a tight prior on a single parameter or a combination of tight priors on multiple parameters. I first obtain Bayesian estimates and then compute the presentvalue government spending multipliers through the dynamic responses of variables of interest to a government spending shock in these sub-models. I find that the multipliers obtained are all in a reasonable range, and the dynamic responses of output, consumption and investment are comparable with other empirical studies shown in Table 1. Moreover,

2 Galí et al. (2007) argue that if the model considers the non-Ricardian agents or rule-of-thumb consumers, who consume all of their current income without any borrowing or saving, then the output multipliers are larger with a crowding-in effect on consumption. Cogan et al. (2010) obtain smaller multipliers since they decrease the fraction of rule-of-thumb consumers and thus lower the influence of the existence of non-Ricardian agents on the effects of fiscal stimulus. 
I forecast the effect of fiscal stimulus in a scenario similar to the 2008/2009 recession in the US, where the public expects a large and temporary increase in government spending to stimulate the economy. Most importantly, the Bayesian combination forecast, which is first generated from a group of representative DSGE models and then averaged on the basis of the posterior model probabilities, is compared with the one generated from a single model that has the best fit. I find that the forecast error of the combination forecast, computed via Bayesian model averaging (BMA), is statistically larger than the individual forecast, obtained from the Smets-Wouters model that has the highest marginal data density. The result obtained from the comparison of the predictive accuracy is no surprise since the individual forecasts, used to compute the combination forecast, are generated from submodels with lower marginal data densities.

The rest of the paper is organized as follows. In Section 2, I describe the economic environment of the Smets-Wouters model. Then I briefly describe the data sources and empirical strategy in Section 3. In Section 4, I present the empirical results. Finally, Section 5 concludes the paper.

Table 1 | Previous Studies on Fiscal Stimulus

\begin{tabular}{|c|c|c|c|c|}
\hline \multirow{2}{*}{ Empirical studies } & \multirow{2}{*}{$\begin{array}{l}\text { Model \& empirical } \\
\text { methodology }\end{array}$} & \multicolumn{3}{|c|}{ Effect of government purchases } \\
\hline & & Y (Multiplier) & Consumption & Investment \\
\hline $\begin{array}{l}\text { Baxter and King } \\
\text { (1993) }\end{array}$ & $\begin{array}{l}\text { Neoclassical framework } \\
\text { Calibration }\end{array}$ & $<1$ & $<0$ & $<0$ \\
\hline $\begin{array}{l}\text { Burnside, } \\
\text { Eichenbaum and } \\
\text { Fisher (2004) }\end{array}$ & $\begin{array}{l}\text { Modified Neoclassical } \\
\text { framework } \\
\text { Calibration }\end{array}$ & - & $<0$ & $>0$ \\
\hline $\begin{array}{l}\text { Cogan, Cwik, Taylor } \\
\text { and Wieland (2010) }\end{array}$ & $\begin{array}{l}\text { Medium-scale New } \\
\text { Keynesian model } \\
\text { Bayesian approach }\end{array}$ & $<1$ & $<0$ & $<0$ \\
\hline $\begin{array}{l}\text { Davig and Leeper } \\
\text { (2011) }\end{array}$ & $\begin{array}{l}\text { Small-scale New } \\
\text { Keynesian model } \\
\text { Calibration }\end{array}$ & $<1$ & $<0$ & - \\
\hline $\begin{array}{l}\text { Galí, López-Salido } \\
\text { and Vallés (2007) }\end{array}$ & $\begin{array}{l}\text { Small-scale New } \\
\text { Keynesian model } \\
\text { Calibration }\end{array}$ & $<1$ & $>0$ & - \\
\hline $\begin{array}{l}\text { Woodford } \\
\text { (2011) }\end{array}$ & $\begin{array}{l}\text { Friction (Frictionless) } \\
\text { DSGE Models } \\
\text { Calibration }\end{array}$ & $<1$ & - & - \\
\hline $\begin{array}{l}\text { Zubairy } \\
\text { (2013) }\end{array}$ & $\begin{array}{l}\text { Medium-scale New } \\
\text { Keynesian model } \\
\text { Bayesian approach }\end{array}$ & $>1$ & $>0$ & $<0$ \\
\hline
\end{tabular}

Note: If the cited study estimates multiple models, then I pick up the results (impact multipliers), shown in the last three columns of Table 1, obtained from the models which are similar to the models adopted in my paper.

Source: Author's classification 


\section{Medium-scale New Keynesian Model}

Compared with Real Business Cycle (RBC) and small-scale New Keynesian models, the Smets-Wouters model is relatively complicated since it includes all kinds of stochastic shocks and nominal and real frictions. ${ }^{3}$ Many empirical studies confirm that the existence of those frictions is helpful in explaining the features of the US business cycle. Below I describe the optimization problems faced by the economic agents under the SmetsWouters model.

1. Households: Each household, denoted by $j$, chooses the amount of consumption $\left(C_{t}\right)$, labour supply $\left(L_{t}\right)$, bond $\left(B_{t}\right)$, investment $\left(I_{t}\right)$, and capital utilization rate $\left(Z_{t}\right)$ to maximize the present value of the non-separable utility function. ${ }^{4}$ It makes the optimal decision subject to the budget constraint and capital accumulation equation. Two AR(1) stochastic shocks directly affect its decision: the shock to the premium in the return to bonds, $\ln \varepsilon_{t}^{b}=\rho_{b} \ln \varepsilon_{t-1}^{b}+\eta_{t}^{b}, \eta_{t}^{b} \sim N\left(0, \sigma_{b}\right)$, and the shock to the price of investment relative to consumption goods, $\ln \varepsilon_{t}^{i}=\rho_{i} \ln \varepsilon_{t-1}^{i}+\eta_{t}^{i}, \eta_{t}^{i} \sim N\left(0, \sigma_{i}\right) .{ }^{5}$ Below is the optimization problem of the representative household,

$$
\begin{gathered}
\text { Max } \quad E_{t} \sum_{s=0}^{\infty}\left\{\frac{1}{1-\sigma_{c}}\left[C_{t+s}(j)-h C_{t+s-1}\right]^{1-\sigma_{c}}\right\} \exp \left[\frac{\sigma_{c}-1}{1+\sigma_{l}} L_{t+s}(j)^{1+\sigma_{l}}\right], \\
\text { s.t. } \quad C_{t+s}(j)+I_{t+s}(j)+\frac{B_{t+s}(j)}{\varepsilon_{t}^{b} R_{t+s} P_{t+s}}-T_{t+s} \leq \frac{B_{t+s-1}(j)}{P_{t+s}}+\frac{W_{t+s}^{h}(j) L_{t+s}(j)}{P_{t+s}} \\
+\frac{R_{t+s}^{k} Z_{t+s}(j) K_{t+s-1}(j)}{P_{t+s}}-a\left[Z_{t+s}(j)\right] K_{t+s-1}(j)+\frac{D_{t+s}}{P_{t+s}}, \\
K_{t}(j)=(1-\delta) K_{t-1}(j)+\varepsilon_{t}^{i}\left[1-S\left(\frac{I_{t}(j)}{I_{t-1}(j)}\right)\right] I_{t}(j),
\end{gathered}
$$

where $\frac{1}{\sigma_{c}}, \frac{1}{\sigma_{l}}$ and $\delta$ measure the elasticity of inter-temporal substitution, Fischer elasticity of labour supply and the depreciation rate. $P_{t}, W_{t}^{h}, R_{t}^{k}, R_{t}, T_{t}$, and $D_{t}$ denote the price level, nominal wage, rental rate on the effective capital, $Z_{t}(j) K_{t-1}(j)$, interest rate, lump-sum net taxes (transfer), and the dividends received by the household.

3 The Smets-Wouters model is constructed on the basis of Smets and Wouters (2003) and Christiano et al. (2005). The model of Smets and Wouters (2003) includes a rich setting of stochastic shocks (ten shocks), and nominal and real frictions. They also refer to the model of Christiano et al. (2005) since some elements in it are helpful for explaining the features of the US business cycle.

$4 \quad$ Basu and Kimball (2002) prove that using non-separable preferences in consumption and labour supply leads to more accurate estimates of the consumption Euler equation.

5 Smets and Wouters (2007) state that the risk premium shock is different from the discount factor (preference) shock. The discount factor shock does not appear in the household's budget constraint, but it directly affects the inter-temporal Euler equation on consumption. 
$a\left[Z_{t+s}(j)\right] K_{t+s-1}(j)$ represents the real costs of changing utilization rate of capital. ${ }^{6}$ Real frictions affect the household's decision via the effect of external habit formation on consumption, characterized by the parameter $h$, and the adjustment costs associated with the investment, measured by the function $S .^{78}$

2. Labour packers: They choose the optimal bundles of differentiated labour, $L_{t}(l)$, to maximize the economic profit on a perfectly competitive labour market. Differentiated labour is packaged first and then sold to the intermediate goods producers,

$$
L_{t}=\left[\int_{0}^{1} L_{t}(l)^{\frac{1}{1+\varepsilon_{t}^{w}}} d l\right]^{1+\varepsilon_{t}^{w}},
$$

where the AR(1) process of wage mark-up shock, $\ln \varepsilon_{t}^{w}=\rho_{w} \ln \varepsilon_{t-1}^{w}+\eta_{t}^{w}, \eta_{t}^{w} \sim N\left(0, \sigma_{w}\right)$, directly affects their choices. Their labour demand combined with the zero profit condition directly affects the optimal decisions of intermediate labour unions.

3. Intermediate labour unions: Each of them, denoted by $l$, chooses the optimal level of wages to maximize the present value of wage income, but their decisions are subject to nominal wage rigidity and labour demand of the labour packers. ${ }^{9}$ Below is the optimization problem of a representative intermediate labour union,

$$
\begin{gathered}
\frac{\operatorname{Max}}{W_{t}(l)} E_{t} \sum_{s=0}^{\infty} \theta_{w}^{s}\left(\frac{\beta^{s} \Xi_{t+s} P_{t}}{\Xi_{t} P_{t+s}}\right)\left[W_{t+s}(l)-W_{t+s}^{h}\right] L_{t+s}(l), \\
\text { s.t. } L_{t+s}(l)=\left[\frac{W_{t+s}(l)}{W_{t+s}}\right]^{-\frac{1+\varepsilon_{t+s}^{w}}{\varepsilon_{t+s}^{t w}}} L_{t+s}, \\
W_{t+s}(l)=\bar{W}_{t}(l)\left(\Pi_{l=1}^{s} \gamma \pi_{t+l-1}^{\chi_{w}} \pi_{*}^{1-\chi_{w}}\right), \quad \text { for } s=1,2, \ldots, \infty
\end{gathered}
$$

where $\Xi$ is the Lagrange multiplier, $1-\theta_{w}$ characterizes the probability that the union can reoptimize its wage, $\frac{\beta^{s} \Xi_{t+s} P_{t}}{\Xi_{t} P_{t+s}}$ is the nominal stochastic discount factor for the union, $\chi_{w}$ measures the wage indexation, $\pi_{t}$ is the gross inflation rate, and $\pi_{*}$ is the steady-state inflation. Those unions that are not able to reoptimize their wages adjust the wages mechanically according to $W_{t-1}(l) \gamma \pi_{t+l-1}^{\chi_{w}} \pi_{*}^{1-\chi_{w}}$.

$6 \quad$ Christiano et al. (2005) argue that the inclusion of the variable capital utilization rate helps generate inflation inertia and the persistence in output when the model has moderate wage and price rigidities.

7 Fuhrer (2000) states that including the external habit formation of consumption in a DSGE framework helps explain the empirical persistence of the consumption expenditure.

8 As mentioned in Christiano et al. (2005), including the capital adjustment costs, which are specified as a function of the change in investment, helps capture the hump-shaped response of investment to various shocks.

9 Christiano et al. (2005) state that taking both wage and price rigidities into consideration helps explain the inflation inertia and output persistence. 
4. Final goods producers: They choose the optimal bundles of differentiated products, $Y_{t}(i)$, to maximize the profit on a perfectly competitive goods market. Differentiated goods are packaged first and then sold to the households as

$$
Y_{t}=\left[\int_{0}^{1} Y_{t}(i)^{\frac{1}{1+\varepsilon_{t}^{p}}} d l\right]^{1+\varepsilon_{t}^{p}},
$$

where the AR(1) process of price mark-up shock, $\ln \varepsilon_{t}^{p}=\rho_{p} \ln \varepsilon_{t-1}^{p}+\eta_{t}^{p}, \eta_{t}^{p} \sim N\left(0, \sigma_{p}\right)$, directly affects their choices. Their output demand combined with the zero-profit condition directly affects the optimal decisions of intermediate goods producers.

5. Intermediate goods producers: Each of them, denoted by $i$, first chooses the optimal level of labour and capital to minimize its total costs. It then chooses the optimal level of prices to maximize the present value of economic profit, but its decisions are subject to nominal price rigidity and the output demand of final goods producers. The total factor productivity shock directly affects its production. Below is the optimization problem of the representative intermediate goods producer,

$$
\begin{aligned}
& \underset{P_{t}(i)}{\operatorname{Max}} \quad E_{t} \sum_{s=0}^{\infty} \theta_{p}^{s}\left(\frac{\beta^{s} \Xi_{t+s} P_{t}}{\Xi_{t} P_{t+s}}\right)\left[\bar{P}_{t}(i)\left(\Pi_{l=1}^{s} \pi_{t+l-1}^{\chi_{p}} \pi_{*}^{1-\chi_{p}}\right)-M C_{t+s}\right] Y_{t+s}(i), \\
& \text { s.t. } Y_{t}(i)=\varepsilon_{t}^{a}\left[Z_{t}(i) K_{t-1}(i)\right]^{\alpha}\left[\gamma^{t} L_{t}(i)\right]^{1-\alpha}-\gamma^{t} \Phi, \\
& Y_{t+s}(i)=Y_{t+s} G^{\prime-1}\left[\frac{P_{t}(i) X_{t, s}}{P_{t+s}} \tau_{t+s}\right], \tau_{t}=\int_{0}^{1} G^{\prime}\left(\frac{Y_{t}(i)}{Y_{t}}\right) \frac{Y_{t}(i)}{Y_{t}} d i, \\
& X_{t, s}=\left\{\begin{array}{c}
1, \quad \text { for } s=0 \\
\left(\prod_{l=1}^{s} \pi_{t+l-1}^{\chi_{p}} \pi_{*}^{1-\chi_{p}}\right), \quad \text { for } s=1,2, \ldots, \infty
\end{array}\right\}
\end{aligned}
$$

where $\alpha$ indicates the capital share, and $\varepsilon_{t}^{\alpha}$ is the total factor productivity and follows the $\mathrm{AR}(1)$ process, $\ln \varepsilon_{t}^{a}=\rho_{a} \ln \varepsilon_{t-1}^{a}+\eta_{t}^{a}, \eta_{t}^{a} \sim N\left(0, \sigma_{a}\right)$. Both $\gamma^{t}$ and $\Phi$ represent the labour-augmenting deterministic growth rate and the fixed costs. $1-\theta_{p}$ characterizes the probability that the firm can reoptimize its price, $\frac{\beta^{s} \Xi_{t+s} P_{t}}{\Xi_{t} P_{t+s}}$ is the nominal stochastic discount factor for the firms, $\chi_{p}$ measures the price indexation, $M C_{t}$ is the nominal marginal costs for the firm, obtained from its cost minimization problem. $G$ is a strictly concave and increasing aggregator function. ${ }^{10}$ Firms that are not able to reoptimize their prices adjust the prices mechanically according to $P_{t}(i) \pi_{t+l-1}^{\chi_{p}} \pi_{*}^{1-\chi_{p}}$.

10 According to Kimball (1995), $\tau_{t}=\int_{0}^{1} G^{\prime}\left(\frac{Y_{t}(i)}{Y_{t}}\right) \frac{Y_{t}(i)}{Y_{t}} d i \approx \int_{0}^{1} P_{t}(i) Y_{t}(i) d i$. That is, $\tau_{t}$ can be explained by the sum of the total revenue obtained by the differentiated goods producers. 
6. Government sector: Fiscal policy is implemented subject to its budget constraint:

$$
P_{t} G_{t}+B_{t-1}=T_{t}+\frac{B_{t}}{R_{t}}
$$

where government spending is expressed relative to the steady-state output path, $g_{t}=\frac{G_{t}}{\gamma^{t} Y_{t}}$ and follows a stationary AR(1) stochastic process, acting as the government spending shock, $\ln \varepsilon_{t}^{g}=\rho_{g} \ln \varepsilon_{t-1}^{g}+\eta_{t}^{g}, \eta_{t}^{g} \sim N\left(0, \sigma_{g}\right)$. The monetary authority follows a modified Taylor rule by gradually adjusting the policy-controlled rate in response to the deviations of output, inflation and output growth rate from their target levels:

$$
\frac{R_{t}}{R^{*}}=\left(\frac{R_{t-1}}{R^{*}}\right)^{\rho_{R}}\left[\left(\frac{\pi_{t}}{\pi_{*}}\right)^{\psi_{\pi}}\left(\frac{Y_{t}}{Y^{*}}\right)^{\psi_{Y}}\right]^{1-\rho_{R}}\left(\frac{\frac{Y_{t}}{Y_{t-1}}}{\frac{Y_{t}^{*}}{Y_{t-1}^{*}}}\right)^{\psi_{\Delta Y}} \varepsilon_{t}^{m},
$$

where monetary policy shock is characterized by $\varepsilon_{t}^{m}$ with a stationary AR(1) process, $\ln \varepsilon_{t}^{m}=\rho_{m} \ln \varepsilon_{t-1}^{m}+\eta_{t}^{m}, \eta_{t}^{m} \sim N\left(0, \sigma_{m}\right)$.

These optimization problems of the agents give rise to a set of nonlinear equilibrium conditions. The usual way to obtain the model solution is log-linearizing those conditions around their steady states to yield a dynamic system of linearized equations. Using the linear solution techniques, one can solve for the policy or state equations, which characterize the dynamic behaviour of the model variables. With the model solutionat hand, one can simulate the data from a calibrated model or estimate the structural parameters with a likelihood-based approach.

\section{Data and Estimation}

Data series are downloaded from the official website of the Federal Reserve Bank of St. Louis, from 1947 Q1 to 2017 Q4. The data series are used to compute observed variables, such as consumption, investment, output, hours, inflation, real wage and interest rate, appearing in a measurement equation. ${ }^{11}$ I follow Smets and Wouters (2007) to choose 1966 Q1 as the starting point for the Bayesian estimation. In Table 2, I include a detailed description of the source of the raw data.

11 I follow Smets and Wouters (2007) to transform the original data before the estimation. 
Table 2 | Description of the Data Sources

\begin{tabular}{|c|c|c|c|}
\hline Title & Series ID & Source & Frequency \\
\hline $\begin{array}{l}\text { Gross Domestic Product: Implicit Price } \\
\text { Deflator }\end{array}$ & GDPDEF & $\begin{array}{l}\text { U.S. Bureau of Economic } \\
\text { Analysis }\end{array}$ & Quarterly \\
\hline Personal Consumption Expenditures & PCEC & $\begin{array}{l}\text { U.S. Bureau of Economic } \\
\text { Analysis }\end{array}$ & Quarterly \\
\hline $\begin{array}{l}\text { Labour Force Status: Civilian Non- } \\
\text { institutional Population }\end{array}$ & LNS10000000 & $\begin{array}{l}\text { U.S. Bureau of Labour } \\
\text { Statistics }\end{array}$ & Quarterly \\
\hline $\begin{array}{l}\text { Real Gross Domestic Product, } 3 \\
\text { Decimal }\end{array}$ & GDPC96 & $\begin{array}{l}\text { U.S. Bureau of Economic } \\
\text { Analysis }\end{array}$ & Quarterly \\
\hline Fixed Private Investment & FPI & $\begin{array}{l}\text { U.S. Bureau of Economic } \\
\text { Analysis }\end{array}$ & Quarterly \\
\hline Civilian Employment & CE16OV & $\begin{array}{l}\text { U.S. Bureau of Labour } \\
\text { Statistics }\end{array}$ & Quarterly \\
\hline $\begin{array}{l}\text { Nonfarm Business Sector: Average } \\
\text { Weekly Hours }\end{array}$ & PRS85006023 & $\begin{array}{l}\text { U.S. Bureau of Labour } \\
\text { Statistics }\end{array}$ & Quarterly \\
\hline $\begin{array}{l}\text { Nonfarm Business Sector: } \\
\text { Compensation Per Hour }\end{array}$ & COMPNFB & $\begin{array}{l}\text { U.S. Bureau of Labour } \\
\text { Statistics }\end{array}$ & Quarterly \\
\hline Effective Federal Funds Rate & FEDFUNDS & $\begin{array}{l}\text { Board of Governors } \\
\text { of the Fed }\end{array}$ & Quarterly \\
\hline \multirow[t]{2}{*}{$\begin{array}{l}\text { 3-Month Treasury Bill: Secondary } \\
\text { Market Rate }\end{array}$} & TB3MS & $\begin{array}{l}\text { Board of Governors } \\
\text { of the Fed }\end{array}$ & Quarterly \\
\hline & Units & Note & Data Range \\
\hline $\begin{array}{l}\text { Gross Domestic Product: Implicit Price } \\
\text { Deflator }\end{array}$ & $2009=100$ & Seasonally Adjusted & $\begin{array}{l}\text { 1947Q1- } \\
\text { 2017Q4 }\end{array}$ \\
\hline Personal Consumption Expenditures & Billions of Dollars & Seasonally Adjusted & $\begin{array}{l}\text { 1947Q1- } \\
\text { 2017Q4 }\end{array}$ \\
\hline $\begin{array}{l}\text { Labour Force Status: Civilian Non- } \\
\text { institutional Population }\end{array}$ & In Thousands & Seasonally Adjusted & $\begin{array}{l}\text { 1947Q1- } \\
\text { 2017Q4 }\end{array}$ \\
\hline $\begin{array}{l}\text { Real Gross Domestic Product, } 3 \\
\text { Decimal }\end{array}$ & Billions of Dollars & Seasonally Adjusted & $\begin{array}{l}\text { 1947Q1- } \\
\text { 2017Q4 }\end{array}$ \\
\hline Fixed Private Investment & Billions of Dollars & Seasonally Adjusted & $\begin{array}{l}\text { 1947Q1- } \\
\text { 2017Q4 }\end{array}$ \\
\hline Civilian Employment & In Thousands & Averaging Monthly Data & $\begin{array}{l}\text { 1947Q1- } \\
\text { 2017Q4 }\end{array}$ \\
\hline $\begin{array}{l}\text { Nonfarm Business Sector: Average } \\
\text { Weekly Hours }\end{array}$ & $2009=100$ & Seasonally Adjusted & $\begin{array}{l}\text { 1947Q1- } \\
\text { 2017Q4 }\end{array}$ \\
\hline $\begin{array}{l}\text { Nonfarm Business Sector: } \\
\text { Compensation Per Hour }\end{array}$ & $2009=100$ & Seasonally Adjusted & $\begin{array}{l}\text { 1947Q1- } \\
\text { 2017Q4 }\end{array}$ \\
\hline Effective Federal Funds Rate & Percent & Averaging Monthly Data & $\begin{array}{l}\text { 1954Q3- } \\
\text { 2017Q4 }\end{array}$ \\
\hline $\begin{array}{l}\text { 3-Month Treasury Bill: Secondary } \\
\text { Market Rate }\end{array}$ & Percent & $\begin{array}{l}\text { Averages of Business Day, } \\
\text { Discount Basis }\end{array}$ & $\begin{array}{c}\text { 1947Q1- } \\
1954 Q 2\end{array}$ \\
\hline
\end{tabular}

Note: Data are downloaded from the official website of the Federal Reserve Bank of St. Louis. With respect to the monthly data that I collect, I transform them to quarterly data by means of simple average.

Source: Federal Reserve Economic Data (FRED) 
I briefly describe several steps of estimating the parameters of interest using the Bayesian approach. First, the model solution is augmented with a measurement equation, which relates the observed variables to the unobserved state variables in a linearized state-space form representation. Second, under the assumptions of normality in the error vector, the Kalman filter can be used to derive the analytical solution for the likelihood function. Third, by specifying the prior distributions of the underlying structural parameters (the priors), the Bayesian estimates can be obtained by combining the prior and the likelihood function using Markov Chain Monte Carlo (MCMC) simulation techniques. Specifically, the sampling algorithm generates draws from a proposal distribution, and those draws are used to approximate the posterior density and compute statistics of interest afterward. ${ }^{12,13}$ Regarding the prior setting, the beta distribution is commonly used as a prior for a parameter whose theoretical domain is between zero and one. In the models, the parameters particularly include the degree of consumption habit, the capacity utilization rate, Calvo's pricing parameter, a price indexation parameter, Calvo's wage parameter, a wage indexation parameter, and the AR(1) coefficient of the exogenous shock. The inverse gamma distribution is an appropriate choice for a parameter whose theoretical domain is positive, such as the standard deviation of the exogenous shock. For the rest of the parameters whose theoretical domains are relatively broad, I use the normal prior. I borrow heavily from Smets and Wouters (2007) for the prior mean and standard deviation of those parameters. Table 3 includes the description of the prior mean and standard deviation for the parameters of interest. Different DSGE sub-models are considered by tightening the prior on a specific parameter or a number of them. That is, for a single prior or a number of priors I set the prior mean to zero or close to zero with a very small standard deviation. ${ }^{14} \mathrm{~A}$ detailed description of those models is listed in Table 4.

12200,000 draws were taken and the first $20 \%$ of the draws are treated as a burn-in sample (I discard the first $20 \%$ of the 200,000 draws). According to the convergence test proposed in Geweke (1992), all the (27) parameters are converged in the baseline model. For the 15 modified models (405 parameters), most of the parameters are converged.

13 To be able to visit the entire domain of the posterior distribution, the recommended acceptance rate is in a range between 0.2 and 0.45 . I follow this recommended range to obtain the posterior estimates, and I particularly find the optimal scale factor by trial and error with the aim of achieving the recommended acceptance rate.

14 Rabanal and Rubio-Ramírez (2005) consider four versions of the small-scale New Keynesian model by fixing the parameters before the estimation. Instead, I tighten priors for certain parameters on Bayesian estimation. However, the results I obtained are in line with their findings. In particular, the models with both price and wage rigidities (Modified Models 9 and 10) surpass the model with only price rigidity (Modified Model 7). Compared to models 7, 8, and 10, the marginal data density obtained in the Modified Model 9 ("EHL” in Rabanal and Rubio-Ramírez, 2005) is the highest. 
Table 3 | Prior Distribution of Parameters

\begin{tabular}{|c|c|c|c|c|}
\hline \multirow{2}{*}{ PRM } & \multirow{2}{*}{ Description } & \multicolumn{3}{|c|}{ Prior } \\
\hline & & Distribution & Mean & Std. Dev. \\
\hline$h$ & Consumption habits & Beta & 0.7 & 0.1 \\
\hline$\sigma_{c}$ & The inter-temporal elasticity of substitution & Normal & 1.5 & 0.37 \\
\hline$\sigma_{1}$ & Fischer elasticity of labour supply & Normal & 2.0 & 0.75 \\
\hline$\varphi$ & Adjustment costs for investment & Normal & 4.0 & 1.5 \\
\hline$\psi$ & The capacity utilization rate & Beta & 0.5 & 0.15 \\
\hline$\theta_{p}$ & Calvo's pricing parameter & Beta & 0.5 & 0.1 \\
\hline$X_{p}$ & Price indexation parameter & Beta & 0.5 & 0.15 \\
\hline$\theta_{w}$ & Calvo's wage parameter & Beta & 0.5 & 0.1 \\
\hline$X_{w}$ & Wage indexation parameter & Beta & 0.5 & 0.15 \\
\hline$\rho_{R}$ & Interest rate smoothing coefficient & Beta & 0.75 & 0.1 \\
\hline$\psi_{Y}$ & Coefficient for reaction to output gap & Normal & 0.125 & 0.05 \\
\hline$\psi_{\Delta r}$ & Coefficient for reaction to output growth rate & Normal & 0.125 & 0.05 \\
\hline$\psi_{\pi}$ & Coefficient for reaction to inflation & Normal & 1.5 & 0.25 \\
\hline$\rho_{a}$ & AR (1) coefficient on TFP shock & Beta & 0.5 & 0.2 \\
\hline$\rho_{i}$ & AR (1) coefficient on IST technology & Beta & 0.5 & 0.2 \\
\hline$\rho_{b}$ & AR (1) coefficient on risk premium shock & Beta & 0.5 & 0.2 \\
\hline$\rho_{g}$ & AR (1) coefficient on Gov spending shock & Beta & 0.5 & 0.2 \\
\hline$\rho_{p}$ & AR (1) coefficient on price mark-up shock & Beta & 0.5 & 0.2 \\
\hline$\rho_{w}$ & AR (1) coefficient on wage mark-up shock & Beta & 0.5 & 0.2 \\
\hline$\rho_{m}$ & AR (1) coefficient on monetary policy shock & Beta & 0.5 & 0.2 \\
\hline$\sigma_{a}$ & Std. Dev. of TFP shock & Inv. Gamma & 0.1 & 2.0 \\
\hline$\sigma_{i}$ & Std. Dev. of IST shock & Inv. Gamma & 0.1 & 2.0 \\
\hline$\sigma_{b}$ & Std. Dev. of risk premium shock & Inv. Gamma & 0.1 & 2.0 \\
\hline$\sigma_{g}$ & Std. Dev. of Gov spending shock & Inv. Gamma & 0.1 & 2.0 \\
\hline$\sigma_{p}$ & Std. Dev. of price mark-up shock & Inv. Gamma & 0.1 & 2.0 \\
\hline$\sigma_{w}$ & Std. Dev. of wage mark-up shock & Inv. Gamma & 0.1 & 2.0 \\
\hline$\sigma_{m}$ & Std. Dev. of monetary policy shock & Inv. Gamma & 0.1 & 2.0 \\
\hline
\end{tabular}

Note: PRM, IST, TFP and Gov are the abbreviations for parameters, investment-specific technology, total factor productivity and government

Source: Smets and Wouters (2007) 
Table 4 | Description of Baseline Model (BM) and Modified Model (MM)

\begin{tabular}{|c|c|c|}
\hline Model & Model description & $\begin{array}{l}\text { Parameters with } \\
\text { tight priors }\end{array}$ \\
\hline Baseline Model (BM) & Includes all the nominal and real frictions. & - \\
\hline $\begin{array}{l}\text { Modified Model } 1 \\
\text { (MM 1) }\end{array}$ & Removes only one real friction, habit formation. & $h$ \\
\hline $\begin{array}{l}\text { Modified Model } 2 \\
\text { (MM 2) }\end{array}$ & $\begin{array}{l}\text { Removes only one real friction, investment adjustment } \\
\text { costs. }\end{array}$ & $\varphi$ \\
\hline $\begin{array}{l}\text { Modified Model } 3 \\
\text { (MM 3) }\end{array}$ & Removes nominal price rigidities. & $\theta_{p^{\prime}} X_{p}$ \\
\hline $\begin{array}{l}\text { Modified Model } 4 \\
\text { (MM 4) }\end{array}$ & Removes nominal wage rigidities. & $\theta_{w^{\prime}} X_{w}$ \\
\hline $\begin{array}{l}\text { Modified Model } 5 \\
\text { (MM 5) }\end{array}$ & $\begin{array}{l}\text { Removes the reaction parameter to output gap } \\
\text { in the policy rule. }\end{array}$ & $\psi_{Y}$ \\
\hline $\begin{array}{l}\text { Modified Model } 6 \\
\text { (MM 6) }\end{array}$ & $\begin{array}{l}\text { Adjusts the reaction parameter to inflation in the policy } \\
\text { rule. }\end{array}$ & $\psi_{\pi}$ \\
\hline $\begin{array}{l}\text { Modified Model } 7 \\
\text { (MM 7) }\end{array}$ & $\begin{array}{l}\text { Allows only the nominal price rigidity without price } \\
\text { indexation. }\end{array}$ & $h, \varphi, \psi, X_{p}, \theta_{w}, X_{w}$ \\
\hline $\begin{array}{l}\text { Modified Model } 8 \\
\text { (MM 8) }\end{array}$ & $\begin{array}{l}\text { Allows only the nominal wage rigidity without wage } \\
\text { indexation. }\end{array}$ & $h, \varphi, \psi, X_{w}, \theta_{p^{\prime}} X_{p}$ \\
\hline $\begin{array}{l}\text { Modified Model } 9 \\
\text { (MM 9) }\end{array}$ & $\begin{array}{l}\text { Allows both the nominal price and wage rigidity } \\
\text { in a forward-looking manner. }\end{array}$ & $h, \varphi, \psi, X_{p} X_{w}$ \\
\hline $\begin{array}{l}\text { Modified Model } 10 \\
\text { (MM 10) }\end{array}$ & $\begin{array}{l}\text { Allows both the nominal price and wage rigidity with } \\
\text { wage indexation. }\end{array}$ & $h, \varphi, \psi, X_{p}$ \\
\hline $\begin{array}{l}\text { Modified Model } 11 \\
\text { (MM 11) }\end{array}$ & $\begin{array}{l}\text { Allows both the nominal price and wage rigidity with } \\
\text { price indexation. }\end{array}$ & $h, \varphi, \psi, X_{w}$ \\
\hline $\begin{array}{l}\text { Modified Model } 12 \\
\text { (MM 12) }\end{array}$ & Allows only one real friction, habit formation. & $h, \varphi, \psi, X_{p}, \theta_{p^{\prime}} X_{w^{\prime}} \theta_{w}$ \\
\hline $\begin{array}{l}\text { Modified Model } 13 \\
\text { (MM 13) }\end{array}$ & $\begin{array}{l}\text { Allows only one real friction, investment adjustment } \\
\text { costs. }\end{array}$ & $h, \psi, X_{p}, \theta_{p^{\prime}}, X_{w^{\prime}} \theta_{w}$ \\
\hline $\begin{array}{l}\text { Modified Model } 14 \\
\text { (MM 14) }\end{array}$ & $\begin{array}{l}\text { Allows only two real frictions, habit formation and } \\
\text { investment adjustment costs. }\end{array}$ & $\psi, \theta_{p^{\prime}}, X_{p}, \theta_{w^{\prime}} X_{w}$ \\
\hline $\begin{array}{l}\text { Modified Model } 15 \\
\text { (MM 15) }\end{array}$ & Removes all the nominal and real frictions. & $h, \varphi, \psi, \theta_{p^{\prime}} X_{p^{\prime}}, \theta_{w^{\prime}} X_{w}$ \\
\hline
\end{tabular}

Note: In Modified Model 6, the prior mean of $\psi_{\pi}$ is set to one to satisfy the Blanchard and Kahn condition. Source: Author's classification

\section{Empirical Results}

In this section, the empirical results are discussed in four parts: (1) Bayesian estimates, (2) Fiscal spending multipliers, (3) Model comparison, and (4) Forecasting the effect of fiscal stimulus. 


\subsection{Bayesian estimates}

Table 5 presents the point estimates for all the kinds of models, the posterior mean in particular. In terms of the baseline model, it seems that the supply-side shocks (total factor productivity shock, price mark-up and wage mark-up shocks) are relatively persistent. This implies that in the long run, those shocks explain a large fraction of the forecast error variance of real variables. As for the reaction parameters in the monetary policy rule, policymakers act aggressively against deviations in the inflation rate. With respect to the parameters associated with nominal price and wage frictions, those estimates imply that the duration of price and wage stickiness are 3.8 and 5.6 quarters, which are close to the micro-evidence. ${ }^{15}$ With respect to other modified models, it is not surprising that I can observe a single estimated parameter or combination of estimated parameters with values equal or close to zero, since I remove a single or multiple frictions by tightening the priors. Those point estimates are used to compute the short-run and long-run effect of fiscal stimulus as well as being inputs for generating the forecasts of the output growth rate in a scenario similar to the 2008/2009 recession in the US, in which the public expects a large and temporary increase in government spending to stimulate the economy.

Table 5 | Posterior Mean

\begin{tabular}{|l|c|c|c|c|c|c|c|c|c|}
\hline \multicolumn{10}{|c|}{ Posterior mean } \\
\hline Model & $\boldsymbol{h}$ & $\boldsymbol{\sigma}_{\boldsymbol{c}}$ & $\boldsymbol{\sigma}_{\boldsymbol{l}}$ & $\boldsymbol{\varphi}$ & $\boldsymbol{\psi}$ & $\boldsymbol{\theta}_{\boldsymbol{p}}$ & $\boldsymbol{X}_{\boldsymbol{p}}$ & $\boldsymbol{\theta}_{\boldsymbol{w}}$ & $\boldsymbol{X}_{\boldsymbol{w}}$ \\
\hline BM & 0.67 & 1.52 & 1.86 & 7.35 & 0.88 & 0.76 & 0.24 & 0.81 & 0.64 \\
\hline MM 1 & 0.10 & 2.64 & 1.69 & 5.98 & 0.91 & 0.74 & 0.27 & 0.78 & 0.62 \\
\hline MM 2 & 0.63 & 1.92 & 2.23 & 0.63 & 0.91 & 0.63 & 0.24 & 0.90 & 0.50 \\
\hline MM 3 & 0.75 & 1.26 & 2.68 & 4.87 & 0.95 & 0.07 & 0.01 & 0.93 & 0.39 \\
\hline MM 4 & 0.35 & 2.08 & 0.31 & 7.13 & 0.88 & 0.60 & 0.29 & 0.08 & 0.05 \\
\hline MM 5 & 0.85 & 1.20 & 2.19 & 7.92 & 0.89 & 0.70 & 0.20 & 0.89 & 0.72 \\
\hline MM 6 & 0.73 & 1.42 & 2.16 & 7.82 & 0.85 & 0.87 & 0.23 & 0.88 & 0.54 \\
\hline MM 7 & 0.01 & 2.32 & 0.40 & 0.04 & 0.06 & 0.89 & 0.07 & 0.06 & 0.05 \\
\hline MM 8 & 0.06 & 2.95 & 2.17 & 0.03 & 0.08 & 0.09 & 0.05 & 0.87 & 0.04 \\
\hline MM 9 & 0.02 & 2.89 & 3.31 & 0.04 & 0.08 & 0.87 & 0.06 & 0.84 & 0.05 \\
\hline MM 10 & 0.03 & 2.88 & 3.45 & 0.07 & 0.08 & 0.87 & 0.04 & 0.84 & 0.61 \\
\hline MM 11 & 0.05 & 2.90 & 3.88 & 0.02 & 0.08 & 0.84 & 0.41 & 0.83 & 0.07 \\
\hline MM 12 & 0.28 & 2.88 & 0.28 & 0.00 & 0.10 & 0.13 & 0.05 & 0.05 & 0.05 \\
\hline MM 13 & 0.01 & 2.94 & 1.34 & 5.11 & 0.06 & 0.13 & 0.05 & 0.06 & 0.07 \\
\hline MM 14 & 0.31 & 2.74 & 0.20 & 4.22 & 0.06 & 0.14 & 0.06 & 0.05 & 0.05 \\
\hline MM 15 & 0.08 & 2.92 & 1.32 & 0.01 & 0.09 & 0.13 & 0.06 & 0.05 & 0.04 \\
\hline
\end{tabular}

15 Bils and Klenow (2004) find that a median frequency of price adjustments is between 4 and 6 months when prices are measured in the US consumer price index (CPI). Nakamura and Steinsson (2008) find that the estimates of the median frequency of price adjustments are roughly between 8 and 11 months by revising the evidence of Bils and Klenow (2004), in which they exclude the price adjustments associated with sales. 
Table 5 | (Continuation)

\begin{tabular}{|l|c|c|c|c|c|c|c|c|c|}
\hline \multirow{2}{*}{ Model } & \multicolumn{10}{|c|}{ Posterior mean } \\
\cline { 2 - 10 } & $\boldsymbol{\rho}_{\boldsymbol{R}}$ & $\boldsymbol{\Psi}_{\boldsymbol{Y}}$ & $\boldsymbol{\Psi}_{\Delta Y}$ & $\boldsymbol{\Psi}_{\boldsymbol{\pi}}$ & $\boldsymbol{\rho}_{a}$ & $\boldsymbol{\rho}_{\boldsymbol{i}}$ & $\boldsymbol{\rho}_{b}$ & $\boldsymbol{\rho}_{g}$ & $\boldsymbol{\rho}_{\boldsymbol{p}}$ \\
\hline BM & 0.79 & 0.05 & 0.24 & 1.69 & 0.96 & 0.80 & 0.33 & 0.98 & 0.91 \\
\hline MM 1 & 0.79 & 0.08 & 0.28 & 1.72 & 0.98 & 0.80 & 0.93 & 0.98 & 0.93 \\
\hline MM 2 & 0.75 & 0.03 & 0.26 & 1.82 & 0.99 & 0.88 & 0.20 & 0.96 & 0.95 \\
\hline MM 3 & 0.84 & 0.03 & 0.23 & 1.70 & 0.98 & 0.99 & 0.21 & 0.95 & 0.97 \\
\hline MM 4 & 0.72 & 0.04 & 0.25 & 1.92 & 0.98 & 0.79 & 0.76 & 0.98 & 0.96 \\
\hline MM 5 & 0.80 & 0.00 & 0.03 & 1.48 & 0.97 & 0.97 & 0.20 & 0.98 & 0.97 \\
\hline MM 6 & 0.81 & 0.06 & 0.25 & 1.00 & 0.95 & 0.75 & 0.30 & 0.99 & 0.84 \\
\hline MM 7 & 0.54 & 0.00 & 0.19 & 1.22 & 0.98 & 0.91 & 0.94 & 0.99 & 0.85 \\
\hline MM 8 & 0.63 & 0.00 & 0.26 & 1.36 & 0.99 & 0.80 & 0.95 & 0.99 & 0.99 \\
\hline MM 9 & 0.69 & 0.06 & 0.28 & 1.41 & 0.99 & 0.72 & 0.94 & 0.99 & 0.82 \\
\hline MM 10 & 0.71 & 0.07 & 0.28 & 1.42 & 0.99 & 0.70 & 0.94 & 0.99 & 0.84 \\
\hline MM 11 & 0.72 & 0.06 & 0.24 & 1.54 & 0.99 & 0.72 & 0.94 & 0.99 & 0.80 \\
\hline MM 12 & 0.40 & 0.00 & 0.14 & 1.26 & 0.99 & 0.82 & 0.77 & 0.99 & 0.99 \\
\hline MM 13 & 0.41 & 0.01 & 0.17 & 1.53 & 0.99 & 0.75 & 0.87 & 0.99 & 0.99 \\
\hline MM 14 & 0.42 & 0.00 & 0.09 & 1.18 & 0.99 & 0.83 & 0.75 & 0.99 & 0.99 \\
\hline MM 15 & 0.42 & 0.00 & 0.16 & 1.52 & 0.99 & 0.75 & 0.86 & 0.99 & 0.99 \\
\hline
\end{tabular}

Table 5 | (Continuation)

\begin{tabular}{|l|c|c|c|c|c|c|c|c|c|}
\hline \multicolumn{10}{|c|}{ Posterior mean } \\
\hline Model & $\boldsymbol{\rho}_{w}$ & $\boldsymbol{\rho}_{\boldsymbol{m}}$ & $\boldsymbol{\sigma}_{\boldsymbol{a}}$ & $\boldsymbol{\sigma}_{\boldsymbol{i}}$ & $\boldsymbol{\sigma}_{\boldsymbol{b}}$ & $\boldsymbol{\sigma}_{g}$ & $\boldsymbol{\sigma}_{\boldsymbol{p}}$ & $\boldsymbol{\sigma}_{\boldsymbol{w}}$ & $\boldsymbol{\sigma}_{\boldsymbol{m}}$ \\
\hline BM & 0.97 & 0.22 & 0.44 & 0.36 & 0.21 & 0.53 & 0.12 & 0.37 & 0.23 \\
\hline MM 1 & 0.97 & 0.09 & 0.46 & 0.41 & 0.04 & 0.53 & 0.13 & 0.40 & 0.25 \\
\hline MM 2 & 0.97 & 0.10 & 0.43 & 1.47 & 0.23 & 0.53 & 0.14 & 0.41 & 0.27 \\
\hline MM 3 & 0.41 & 0.13 & 0.44 & 0.91 & 0.21 & 0.52 & 0.82 & 0.48 & 0.23 \\
\hline MM 4 & 0.99 & 0.22 & 0.45 & 0.38 & 0.08 & 0.52 & 0.14 & 1.55 & 0.25 \\
\hline MM 5 & 0.64 & 0.18 & 0.44 & 0.29 & 0.22 & 0.52 & 0.12 & 0.39 & 0.23 \\
\hline MM 6 & 0.94 & 0.27 & 0.45 & 0.39 & 0.22 & 0.53 & 0.13 & 0.36 & 0.23 \\
\hline MM 7 & 0.98 & 0.17 & 0.50 & 0.63 & 0.03 & 0.55 & 0.13 & 1.81 & 0.37 \\
\hline MM 9 & 0.97 & 0.22 & 0.51 & 0.73 & 0.03 & 0.56 & 0.86 & 0.37 & 0.73 \\
\hline MM 10 & 0.98 & 0.09 & 0.57 & 0.90 & 0.03 & 0.56 & 0.25 & 0.37 & 0.29 \\
\hline MM 11 & 0.98 & 0.08 & 0.57 & 0.92 & 0.03 & 0.56 & 0.20 & 0.37 & 0.27 \\
\hline MM 12 & 0.99 & 0.37 & 0.50 & 0.62 & 0.04 & 0.53 & 0.47 & 2.21 & 0.34 \\
\hline MM 13 & 0.99 & 0.33 & 0.51 & 0.80 & 0.03 & 0.54 & 0.62 & 2.35 & 0.36 \\
\hline MM 14 & 0.99 & 0.35 & 0.49 & 0.55 & 0.04 & 0.54 & 0.46 & 2.02 & 0.33 \\
\hline MM 15 & 0.99 & 0.33 & 0.50 & 0.79 & 0.03 & 0.54 & 0.58 & 2.81 & 0.35 \\
\hline
\end{tabular}

Source: Author's calculation 


\subsection{Fiscal spending multipliers}

In Table 6, I follow Mountford and Uhlig (2009) by computing the present-value spending multipliers, which measure the increase in present value of output over the next $k$ periods when the spending shock hits the economyat the time $t$. Several findings can be read from the tables. First, overall the estimated output multipliers vary from zero to one in their absolute values. An increase in government purchasing pushes up the aggregate demand and leads firms to hire more workers due to a higher price, and this results in a higher real wage or real marginal costs. An intra-temporal substitution effect occurs since the households work harder and substitute consumption for leisure in response to a higher real wage. However, the inter-temporal effect crowds out the private spending since the monetary policy is tightened aggressively to combat inflation. In addition, a negative wealth effect appears because the government purchasing is financed by the same amount of lump-sum taxes, and this results in decreases in both consumption and leisure. ${ }^{16}$ As a result, the first finding implies that both the negative wealth effect and the inter-temporal substitution effect (crowding-out effect) surpasses the intra-temporal substitution effect.The result is in line with some studies which take a passive fiscal policy (the government spending is financed by the lump-sum tax) and the aggressive monetary policy into consideration. In New Keynesian DSGE models, Davig and Leeper (2011) show that the present-value spending multipliers are less than 1 in regime-switching and fixed-regime models. Moreover, Galí et al. (2007) state that the spending multipliers are less than when one does not take into account the rule-of-thumb households. Second, the crowding-out effect becomes larger and larger over time, and consequently the output multipliers drop gradually. In the long run, the effect of a temporary and large increase in government purchasing on the economy is likely to be negative. This quantitative result is in line with the findings of Uhlig (2010) and Cogan et al. (2010) in a neoclassical and medium-scale New Keynesian model respectively. Third, it is consistent with the argument of Davig and Leeper (2011) that the negative impact of government purchasing on output (private spending) is smaller when the monetary policy is conducted less aggressively, or it can be alternatively explained by a smaller intertemporal substitution effect on private spending. Fourth, by comparing MM 14 with 15, the negative impact of government purchasing on consumption becomes larger when the real frictions are removed, the external habit formation on consumption in particular. This result is consistent with the finding of Burnside et al. (2004) in that the habit formation decreases the fall in consumption. Fifth, by comparing the baseline model with MM 3, MM 8, MM 12, MM 13, MM 14 and MM 15, the negative impact of government purchasing on investment becomes larger when the nominal friction, price rigidity in particular, is removed. This result is line with the argument stated in Davig and Leeper (2011) that when prices are flexible, an increase in government purchase raises the price level sharply, leading the policy makers to raise the interest rate sharply, resulting in lower investment.

16 The wealth effect limits the effects of expansionary fiscal policy since individuals expect rationally that increased government borrowing today will require higher taxes in future. As a result, to make the consumption pattern smooth, they will consume less or save more to finance future consumption. 
Table 6A | Present Value Multipliers for Output

\begin{tabular}{|l|c|c|c|c|c|}
\hline Model & Quarter 1 & Quarter 5 & Quarter 10 & Quarter 20 & Quarter 40 \\
\hline BM & 0.91 & 0.75 & 0.53 & 0.35 & 0.22 \\
\hline MM 1 & 0.69 & 0.59 & 0.45 & 0.31 & 0.18 \\
\hline MM 2 & 0.86 & 0.63 & 0.32 & 0.09 & -0.03 \\
\hline MM 3 & 0.90 & 0.68 & 0.38 & 0.17 & 0.05 \\
\hline MM 4 & 0.94 & 0.86 & 0.76 & 0.65 & 0.50 \\
\hline MM 5 & 0.99 & 0.88 & 0.64 & 0.36 & 0.21 \\
\hline MM 6 & 0.94 & 0.83 & 0.68 & 0.57 & 0.44 \\
\hline MM 7 & 0.96 & 0.95 & 0.92 & 0.88 & 0.83 \\
\hline MM 8 & 0.70 & 0.63 & 0.57 & 0.51 & 0.46 \\
\hline MM 9 & 0.48 & 0.43 & 0.37 & 0.33 & 0.30 \\
\hline MM 10 & 0.48 & 0.41 & 0.35 & 0.31 & 0.29 \\
\hline MM 11 & 0.49 & 0.41 & 0.34 & 0.30 & 0.28 \\
\hline MM 12 & 0.99 & 0.92 & 0.84 & 0.80 & 0.75 \\
\hline MM 13 & 0.70 & 0.65 & 0.61 & 0.60 & 0.58 \\
\hline MM 14 & 0.96 & 0.93 & 0.89 & 0.87 & 0.84 \\
\hline MM 15 & 0.71 & 0.67 & 0.64 & 0.63 & 0.61 \\
\hline
\end{tabular}

Note: The present value multipliers for output are computed based on the impulse response of output to a government spending shock. In particular, the values in the column "Quarter 1" are impact multipliers. Source: Author's calculation

Table 6B | Present Value Multipliers for Consumption

\begin{tabular}{|l|c|c|c|c|c|}
\hline Model & Quarter 1 & Quarter 5 & Quarter 10 & Quarter 20 & Quarter 40 \\
\hline BM & -0.13 & -0.28 & -0.46 & -0.49 & -0.41 \\
\hline MM 1 & -0.46 & -0.53 & -0.57 & -0.56 & -0.48 \\
\hline MM 2 & -0.07 & -0.20 & -0.38 & -0.46 & -0.37 \\
\hline MM 3 & -0.09 & -0.20 & -0.31 & -0.28 & -0.18 \\
\hline MM 4 & -0.12 & -0.19 & -0.23 & -0.21 & -0.17 \\
\hline MM 5 & -0.05 & -0.14 & -0.33 & -0.51 & -0.47 \\
\hline MM 6 & -0.10 & -0.23 & -0.37 & -0.38 & -0.32 \\
\hline MM 7 & -0.18 & -0.18 & -0.18 & -0.19 & -0.19 \\
\hline MM 8 & -0.51 & -0.55 & -0.56 & -0.57 & -0.57 \\
\hline MM 9 & -0.86 & -0.88 & -0.90 & -0.91 & -0.91 \\
\hline MM 10 & -0.85 & -0.89 & -0.91 & -0.92 & -0.91 \\
\hline MM 11 & -0.86 & -0.91 & -0.94 & -0.95 & -0.95 \\
\hline MM 12 & -0.07 & -0.11 & -0.13 & -0.13 & -0.12 \\
\hline MM 13 & -0.48 & -0.48 & -0.48 & -0.47 & -0.47 \\
\hline MM 14 & -0.07 & -0.08 & -0.09 & -0.09 & -0.09 \\
\hline MM 15 & -0.42 & -0.44 & -0.45 & -0.44 & -0.44 \\
\hline
\end{tabular}

Note: The present value multipliers for output are computed based on the impulse response of output to a government spending shock. In particular, the values in the column "Quarter 1" are impact multipliers. Source: Author's calculation 
Table 6C | Present Value Multipliers for Investment

\begin{tabular}{|l|c|c|c|c|c|}
\hline Model & Quarter 1 & Quarter 5 & Quarter 10 & Quarter 20 & Quarter 40 \\
\hline BM & -0.09 & -0.21 & -0.37 & -0.44 & -0.29 \\
\hline MM 1 & -0.09 & -0.23 & -0.48 & -0.61 & -0.47 \\
\hline MM 2 & -0.63 & -1.08 & -1.27 & -0.99 & -0.50 \\
\hline MM 3 & -0.24 & -0.54 & -0.79 & -0.56 & -0.13 \\
\hline MM 4 & -0.01 & -0.03 & -0.08 & -0.09 & -0.05 \\
\hline MM 5 & -0.02 & -0.10 & -0.29 & -0.43 & -0.23 \\
\hline MM 6 & -0.01 & -0.01 & 0.05 & 0.14 & 0.11 \\
\hline MM 7 & -0.07 & -0.15 & -0.26 & -0.35 & -0.47 \\
\hline MM 8 & -0.21 & -0.42 & -0.69 & -0.92 & -1.20 \\
\hline MM 9 & -0.20 & -0.40 & -0.63 & -0.83 & -1.05 \\
\hline MM 10 & -0.21 & -0.40 & -0.64 & -0.84 & -1.05 \\
\hline MM 11 & -0.19 & -0.38 & -0.63 & -0.83 & -1.02 \\
\hline MM 12 & -0.27 & -0.58 & -0.91 & -0.99 & -1.00 \\
\hline MM 13 & -0.28 & -0.56 & -0.84 & -0.96 & -1.10 \\
\hline MM 14 & -0.35 & -0.53 & -0.73 & -0.83 & -0.83 \\
\hline MM 15 & -0.18 & -0.37 & -0.55 & -0.62 & -0.69 \\
\hline
\end{tabular}

Note: The present value multipliers for output are computed based on the impulse response of output to a government spending shock. In particular, the values in the column "Quarter 1" are impact multipliers. Source: Author's calculation

\subsection{Model comparison}

Model comparison is quite straightforward using the Bayesian approach.The Bayes factor is the ratio of two marginal data densities, each of which is the integral value and conditional on different models. If the value of the Bayes factor is larger than one, then the model I consider in the numerator of the Bayes factor is more strongly supported by the data than another one. However, the marginal data density conditional on a specific model can sometimes be difficult to calculate since it involves integrating out the posterior kernel with respect to a set of structural parameters. In this paper, I use both the Laplace approximation and the Modified Harmonic Mean Estimator (MHME) to obtain the marginal data density. Table 7 presents the log marginal data density, which is computed using both the Laplace approximation method and the MHME, for all kinds of models. In addition, the Bayes factor is computed by taking the difference between the log marginal data density of the baseline model and a specific modified model on the basis of the MHME. I find that the baseline model with all nominal and real frictions surpasses all the other models. Consistent with 
Burnside et al. (2004), compared to a frictionless model (Modified Model 15), it is important to include the real frictions of the habit formation on consumption and adjustment costs on investment in the model (Modified Model 14). In particular, when I remove it from the model, I observe a jump in the Bayes factor. In line with the findings of Rabanal and Rubio-Ramírez (2005), the model with sticky price and wage as well as their indexations (Modified Model 10 and 11) surpasses the model with only sticky price (MM 7). In addition, comparing only nominal price friction (MM 7) with the wage friction (MM 8), the nominal price rigidity is relatively important. Lastly, the basic RBC model is surpassed by most of the other models. The log marginal data densities computed in Table 7 play important roles in determining the posterior model probabilities, which are used as the weights for the combination forecast.

Table 7| Log Marginal Data Density

\begin{tabular}{|c|c|c|c|}
\hline \multirow[b]{2}{*}{ Model } & \multicolumn{2}{|c|}{ Log marginal data density } & \multirow[b]{2}{*}{ Bayes factor } \\
\hline & $\begin{array}{c}\text { Laplace } \\
\text { approximation }\end{array}$ & $\begin{array}{c}\text { Modified } \\
\text { harmonic mean }\end{array}$ & \\
\hline BM & $-1,219.96$ & $-1,219.42$ & - \\
\hline MM 6 & $-1,238.86$ & $-1,238.79$ & 19.37 \\
\hline MM 5 & $-1,254.50$ & $-1,256.48$ & 37.06 \\
\hline MM 1 & $-1,262.20$ & $-1,261.73$ & 42.31 \\
\hline MM 4 & $-1,270.22$ & $-1,272.12$ & 52.70 \\
\hline MM 2 & $-1,317.46$ & $-1,309.12$ & 89.70 \\
\hline MM 3 & $-1,387.11$ & $-1,389.41$ & 169.99 \\
\hline MM 9 & $-1,447.89$ & $-1,404.77$ & 185.35 \\
\hline MM 10 & $-1,445.37$ & $-1,405.87$ & 186.45 \\
\hline MM 11 & $-1,448.45$ & $-1,406.90$ & 187.48 \\
\hline MM 7 & $-1,506.67$ & $-1,450.29$ & 230.87 \\
\hline MM 12 & $-1,526.91$ & $-1,504.76$ & 285.34 \\
\hline MM 14 & $-1,537.91$ & $-1,519.98$ & 300.56 \\
\hline MM 15 & $-1,567.48$ & $-1,528.05$ & 308.63 \\
\hline MM 13 & $-1,592.30$ & $-1,546.14$ & 326.72 \\
\hline MM 8 & $-1,681.84$ & $-1,636.31$ & 416.89 \\
\hline
\end{tabular}

Source: Author's calculation 


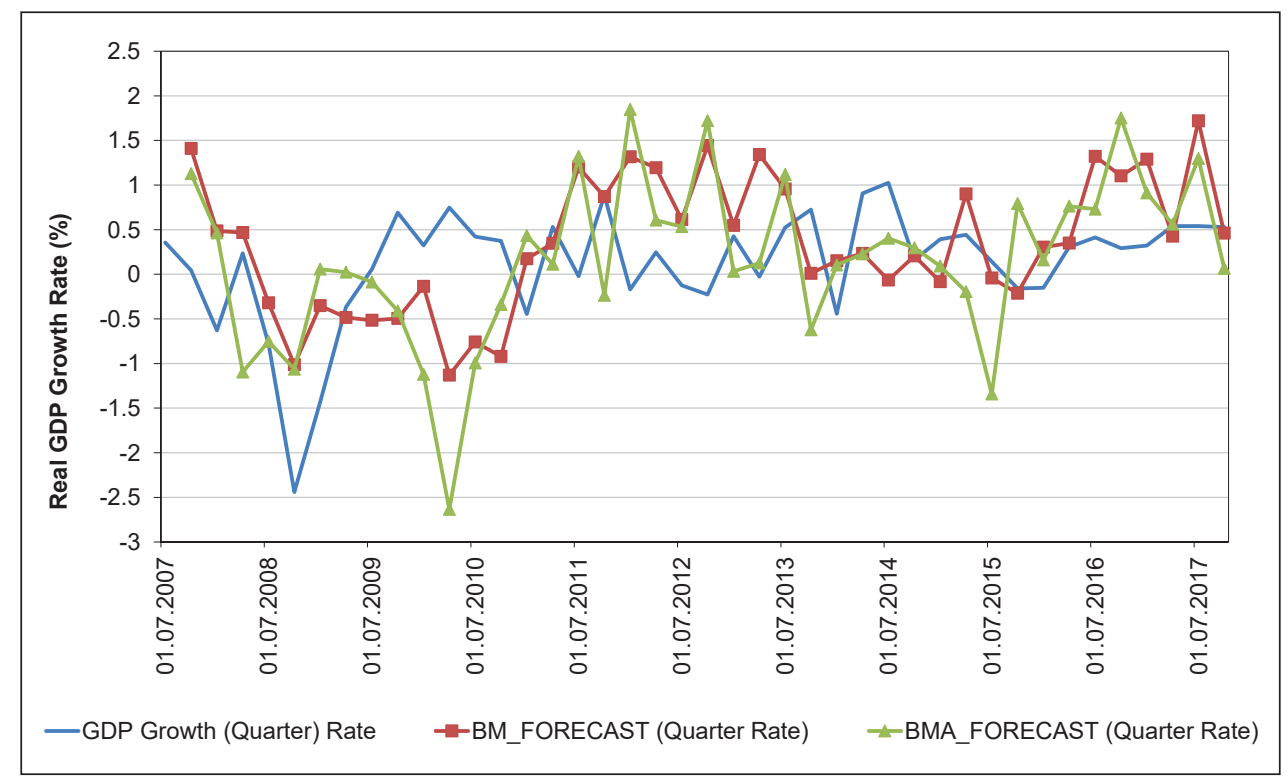

Source: Author's calculation and Federal Reserve Economic Data (FRED)

\subsection{Forecasting the effect of fiscal stimulus}

In this forecasting exercise, the economic environment mixes both deterministic and stochastic shocks. ${ }^{17}$ At the beginning of the period, a negative risk premium shock occurs, which reflects the inefficiency in the financial sector, and the central bank responds to it by lowering the funds rate. That is, a combination of negative demand and an expansionary monetary policy shock initially hits the economy. Later, the economic agents expect the government to temporarily and greatly increase its purchases. To be precise, I assume that a deterministic government spending shock hits the economy 8 quarters after the beginning. ${ }^{18,19}$

According to the posterior estimates, the posterior mean in particular, obtained in Table 5, I generate the forecasts of the output growth rate individually from a group

17 Cogan et al. (2010) also simulate fiscal stimulus by using the Smets-Wouters model. In particular, they assume a constant funds rate for up to 2 years and it then follows back to the stabilizing rule. However, the period of monetary accommodation only causes a modest increase in the government spending multipliers. The Smets-Wouters model I use in my paper is similar to their model. However, I do not take the accommodative monetary policy into consideration; instead, I create a scenario with a mixture of deterministic and stochastic shocks, occurring in different time periods.

18 The size of the deterministic shock (fiscal stimulus) is treated the same over a period of time.

19 The timing of the deterministic shock and the size of the stochastic shock are chosen to match the reality closely. Specifically, I assume this by choosing the third quarter of 2007 as the initial period when the stochastic shock occurs and the second quarter of 2009 as the time point when the deterministic shock hits the economy. 
of representative DSGE models in the economic environment described above. ${ }^{20}$ In particular, the representative DSGE models that are chosen include a medium-scale New Keynesian model (baseline model), a small-scale New Keynesian model (MM 7), an extended version of the small-scale New Keynesian model (MM 9), an extended version of the RBC model (Modified Model 14), and a frictionless RBC model (Modified Model 15). The forecast generated by the baseline model (single forecast) that has the best fit is then compared to the combination forecast calculated using the BMA approach. ${ }^{21}$ Specifically, the weights for the combined forecast are determined on the basis of their posterior model probabilities, calculated from their corresponding marginal data densities. Under the univariate regression framework, Wright (2009) argues that combination forecasts are more accurate if the equal weight used for each individual forecast of US inflation is replaced with the posterior model probability. Similar results are also found in Jacobson and Karlsson (2004) for forecasting Swedish inflation rates. Figure 1 shows the single and the Bayesian combination forecasts of the output growth rate with real observed data. ${ }^{22}$

In Figure 1, the simulated forecast generated from the baseline model roughly captures the time series pattern of the real GDP growth rate. In particular, the economy experiences a negative GDP growth rateat the beginning due to the negative risk premium shock, which is used to characterize the breakdown of the financial and capital market in 2007.The growth rates then rise sharply after the increase in government spending, and it continues to rise for some time. However, the size of spending effects on output growth drops gradually since the public understands the government spending is temporary.

By contrast, the Bayesian combination forecast does not capture the dynamics of the real GDP growth rate well. According to the modified Diebold-Mariano (DM) test proposed in Harvey et al. (1997), the forecast error of the Bayesian combination forecast is statistically larger than the individual forecast generated from the Smets-Wouters model. It is no surprise to obtain the result of the comparison since the individual forecasts that I take for the computation of the combination forecast come from the sub-models of the SmetsWoters model with lower marginal data densities.

\section{Conclusion}

In this paper, I study the effect of large and temporary government purchasing on economic activity. I take a top-down approach by generalizing the structural DSGE model of Smets and Wouters (2007), ranging from a frictionless Real Business Cycle (RBC) model to a medium-scale New Keynesian model with many nominal and real frictions. Specifically, I proxy various simpler DSGE sub-models by imposing a tight prior on a single parameter or a combination of tight priors on multiple parameters. I estimate various versions of the Smets-Wouters model using a Bayesian approach, and the Bayesian estimates are used

20 The forecasting results are not sensitive to the choice of the posterior mode or mean since their estimates are close to each other.

21 Hoeting et al. (1999) provide a tutorial on the BMA approach.

22 The y-axis is non-annualized real GDP growth rate presented in percent. 
to compute the present-value spending multipliers and the Bayesian forecasts of the output growth rate. Overall, the values of spending multipliers are obtained in a reasonable range.The forecast error of the Bayesian combination forecast is statistically larger than the individual forecast generated from the Smets-Wouters model that has the best fit among those DSGE models.

As for future research, I plan to study the fiscal stimulus by considering incomplete markets ("non-Ricardian" agents) and a rich setting of fiscal policy, including the labour and capital income tax rates in particular in the model.

\section{References}

Basu, S., Kimball, M. (2002). Long-Run Labour Supply and the Elasticity of Intertemporal Substitution for Consumption. Manuscript, University of Michigan. http://www-personal. umich.edu/ mkimball/pdf/cee_oct02-3.pdf

Baxter, M., King, R. G. (1993). Fiscal Policy in General Equilibrium. American Economic Review, 315-334.

Bils, M., Klenow, P. J. (2004). Some Evidence on the Importance of Sticky Prices. Journal of Political Economy, 112(5), 947-985, https://doi.org/10.1086/422559

Burnside, C., Eichenbaum, M., Fisher, J. D. (2004). Fiscal Shocks and Their Consequences. Journal of Economic Theory, 115(1), 89-117, https://doi.org/10.1016/s0022-0531(03)00252-7

Christiano, L. J., Eichenbaum, M., Evans, C. L. (2005). Nominal Rigidities and the Dynamic Effects of a Shock to Monetary Policy. Journal of Political Economy, 113(1), 1-45, https://doi. org/10.1086/426038

Christiano, L. J., Eichenbaum, M., Rebelo, S. (2011). When is the Government Spending Multiplier Large? Journal of Political Economy, 119(1), 78-121, https://doi. org/10.1086/659312

Cogan, J. F., Cwik, T., Taylor, J. B., Wieland, V. (2010). New Keynesian versus Old Keynesian Government Spending Multipliers. Journal of Economic Dynamics and Control, 34(3), 281-295, https://doi.org/10.1016/j.jedc.2010.01.010

Davig, T., Leeper, E. M. (2011). Monetary-Fiscal Policy Interactions and Fiscal Stimulus. European Economic Review, 55(2), 211-227, https://doi.org/10.1016/j.euroecorev.2010.04.004

Fuhrer, J. C. (2000). Habit Formation in Consumption and its Implications for Monetary-Policy Models. American Economic Review, 90(3), 367-390, https://doi.org/10.1257/aer.90.3.367

Galí, J., López-Salido, J. D., Vallés, J. (2007). Understanding the Effects of Government Spending on Consumption. Journal of the European Economic Association, 5(1), 227-270, https://doi.org/10.1162/jeea.2007.5.1.227

Geweke, J. (1992). Evaluating the Accuracy of Sampling-Based Approaches to the Calculation of Posterior Moments. Bayesian Statistics, 4, 169-193.

Harvey, D., Leybourne, S., Newbold, P. (1997). Testing the Equality of Prediction Mean Squared Errors. International Journal of Forecasting, 13(2), 281-291, https://doi.org/10.1016/ s0169-2070(96)00719-4

Hoeting, J. A., Madigan, D., Raftery, A. E., Volinsky, C. T. (1999). Bayesian Model Averaging: A Tutorial. Statistical Science, 14(4), 382-417. 
Jacobson, T., Karlsson, S. (2004). Finding Good Predictors for Inflation: A Bayesian Model Averaging Approach. Journal of Forecasting, 23(7), 479-496, https://doi.org/10.1002/ for.924

Kimball, M. S. (1995). The Quantitative Analytics of the Basic Neomonetarist Model. Journal of Money, Credit and Banking, 27(4), 1241-1277, https://doi.org/10.2307/2078048

Mountford, A., Uhlig, H. (2009). What are the Effects of Fiscal Policy Shocks? Journal of Applied Econometrics, 24(6), 960-992, https://doi.org/10.1002/jae.1079

Nakamura, E., Steinsson, J. (2008). Five Facts about Prices: A Reevaluation of Menu Cost Models. The Quarterly Journal of Economics, 123(4), 1415-1464, https://doi.org/10.1162/ qjec.2008.123.4.1415

Rabanal, P., Rubio-Ramírez, J. F. (2005). Comparing New Keynesian Models of the Business Cycle: A Bayesian Approach. Journal of Monetary Economics, 52(6), 1151-1166, https://doi.org/10.1016/j.jmoneco.2005.08.008

Smets, F., Wouters, R. (2003). An Estimated Dynamic Stochastic General Equilibrium Model of the Euro Area. Journal of the European Economic Association, 1(5), 1123-1175, https://doi.org/10.1162/154247603770383415

Smets, F., Wouters, R. (2007). Shocks and Frictions in US Business Cycles: A Bayesian DSGE Approach. American Economic Review, 97(3), 586-606, https://doi.org/10.1257/ aer.97.3.586

Uhlig, H. (2010). Some Fiscal Calculus. American Economic Review, 100(2), 30-34, https://doi.org/10.1257/aer.100.2.30

Whalen, C. J., Reichling, F. (2015). The Fiscal Multiplier and Economic Policy Analysis in the United States. Contemporary Economic Policy, 33(4), 735-746, https://doi. org/10.1111/coep.12104

Woodford, M. (2011). Simple Analytics of the Government Expenditure Multiplier. American Economic Journal: Macroeconomics, 3(1), 1-35, https://doi.org/10.1257/mac.3.1.1

Wright, J. H. (2009). Forecasting US Inflation by Bayesian Model Averaging. Journal of Forecasting, 28(2), 131-144, https://doi.org/10.1002/for.1088

Zubairy, S. (2014). On Fiscal Multipliers: Estimates from a Medium Scale DSGE Model. International Economic Review, 55(1), 169-195, https://doi.org/10.1111/iere.12045 